\title{
Balance and Gait Impairment in Persons with Multiple Sclerosis with the Absence of Clinical Disability
}

\author{
Klinik Yeti Yitimi Olmayan Multipl Sklerozlu Bireylerde Denge ve Yürüyüş Bozukluğu
}

\author{
(1) Hatice Ayan ${ }^{1}$, (1) Özge Ertekin², (1) Turhan Kahraman³, (1) Serkan Özakbaş4 \\ ${ }^{1}$ Izmir University of Economics Vocational School of Health Services, Department of Physiotherapy, Dokuz Eylul University, \\ Institute of Health Sciences, Izmir, Turkey \\ 2Dokuz Eylul University School of Physical Therapy and Rehabilitation, Izmir, Turkey \\ 3/zmir Katip Celebi University Faculty of Health Sciences, Department of Physiotherapy and Rehabilitation, Izmir, Turkey \\ 4Dokuz Eylul University Faculty of Medicine, Department of Neurology, Izmir, Turkey
}

\begin{abstract}
Objective: Impaired balance is one of the most important risk factors for falls in persons with multiple sclerosis (pwMS). The aim was to evaluate balance and gait performance in pwMS with the absence of clinical disability (pwMS-AD) compared with pwMS with minimal disability (MD) and healthy controls (HC).

Materials and Methods: Nineteen pwMS-AD were assessed using the Expanded Disability Status scale (EDSS) score $\leq 1.5,16$ pwMS-MD (2.0 $\leq$ EDSS $\leq 3.0)$, and $39 \mathrm{HC}$ were assessed using a posturography. Limits of stability (LOS), postural stability (PS) and fall risk index tests were performed. The Brief-Balance Evaluation Systems Test (Brief-BESTest), Activities-Specific Balance Confidence (ABC) scale, timed 25 foot walk test (T25FW) and 12-Item MS walking scale (MSWS-12) were used.

Results: Significant differences were observed between pwMS-AD and pwMS-MD in terms of PS (overall, anteroposterior, mediolateral), Brief-BESTest, T25FW, and MSWS-12 ( $<<0.05)$. The stability limits (overall, forward LOS score) of the pwMS-AD group decreased significantly compared with the HC ( $<0.05)$. There was also a significant difference in mediolateral PS, fall risk, Brief-BESTest and T25FW scores ( $<<0.05)$, but no significant difference was found in the ABC scale score $(\mathrm{p}=0.543)$ between pwMS-AD and HC.

Conclusion: The results showed that pwMS with the absence of clinical disability had better balance and gait performance than pwMS with minimal disability, but compared with HC, pwMS-AD have impaired balance and gait performance; however, subjective confidence in balance is not significantly different. PwMS$\mathrm{AD}$ should be assessed regularly for the early detection of impaired balance and fall risk, even if there are no reported problems related to balance and gait.
\end{abstract}

Keywords: Multiple sclerosis, balance, gait, disability

$\ddot{O} \mathbf{z}$

Amaç: Denge bozukluğu, multipl sklerozlu bireylerde (pwMS) düşmeler için en önemli risk faktörlerinden biridir. Çalışmamızın amacı, klinik yeti yitimi olmayan MS'li bireylerde denge ve yürüyüş performansını değerlendirmek, minimum yeti yitimine sahip MS'lilerle (pwMS-MD) ve sağlıklı kontrollerle (HC) karşılaştırmaktır.

Gereç ve Yöntem: Genişletilmiş Engellilik Durum ölçeği (EDSS) skoru $\leq 1,5$ olan 19 MS'li birey, minimal yeti yitimine sahip (2,0 1 EDSS $\leq 3,0) 16$ MS'li ve 39 sağlıklı kontrol posturografi kullanılarak stabilite limitleri (LOS), postural stabilite (PS) ve düşme riski açısından değerlendirildi. Ayrıca Brief-Balance Evaluation Systems Test (Brief-BESTest), Aktiviteye Spesifik Denge Güvenlik skalası (ABC), Zamanlı 25 adım yürüme testi (T25FW) ve MS Yürüyüş Ölç̧ği (MSWS-12) kullanıld1.

Bulgular: Yeti yitimi olmayan ve minimal yeti yitimine sahip MS grupları karşılaştırıldı ğında, postüral stabilite (genel, anteroposterior, mediolateral), Brief-BESTest, T25FW ve MSWS-12 açısından anlamlı farklılıklar gözlendi ( $<<0,05)$. Yeti yitimi olmayan MS'li bireyler (pwMS-AD) ile sağlıklı kontroller karşılaştırıldığında ise, pwMS-AD grubunun LOS (genel, ön LOS skorları) anlamlı olarak daha düşüktü ( $\mathrm{p}<0,05)$. İki grup arasında mediolateral PS, düşme riski, Brief-BESTest ve T25FW skorları açısından da anlamlı fark vardı $(\mathrm{p}<0,05)$, ancak ABC skorunda $(\mathrm{p}=0,543)$ ise anlamlı bir fark yoktu.

Address for Correspondence/Yazışma Adresi: Hatice Ayan, Izmir University of Economics Vocational School of Health Services, Department of Physiotherapy Dokuz Eylul University, Institute of Health Sciences, Izmir, Turkey

Phone: +90 5072104257 E-mail: hatice.ayan@ieu.edu.tr ORCID: orcid.org/0000-0002-6641-3540

Received/Geliş Tarihi: 30.10 .2019 Accepted/Kabul Tarihi: 22.05 .2020

${ }^{\circ}$ Copyright 2020 by Turkish Neurological Society

Turkish Journal of Neurology published by Galenos Publishing House. 


\section{$\ddot{O} \mathbf{z}$}

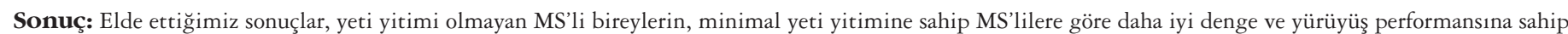

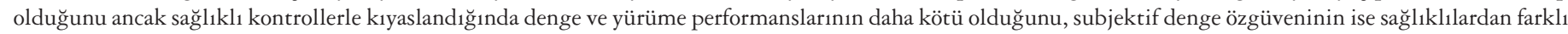

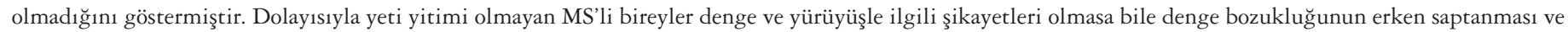
düşme riskinin önlenmesi için düzenli olarak değerlendirilmelidir.

Anahtar Kelimeler: Multipl skleroz, denge, yürüyüş, yeti yitimi

\section{Introduction}

Multiple sclerosis (MS) is a chronic and progressive autoimmune disease that causes inflammation and demyelination in the central nervous system (CNS) (1). It is also an important cause of nontraumatic disability affecting the CNS in young and middle-aged individuals in high-income countries (2).

Balance disorder is one of the initial symptoms of MS (3). Balance is achieved through the interaction of sensory (e.g. proprioceptive, visual, vestibular system), motor (e.g. muscle activity) and cognitive (e.g. attention, conscious information processing) systems to obtain information about the environment (4). For many persons with MS (pwMS), balance and gait disturbance is a major problem because it restricts routine activities and increases the risk of injury due to falls (5). It is important to assess the inadequacy of balance control with clinical scales, but such tests are more sensitive to MS with a moderate or severe disability. Therefore, minor balance deficits may not be detected by clinical scales alone in patients with mild and low disability (6).

Balance has been investigated in the MS population, but there has been insufficient focus on subclinical balance disorders. Such studies are thought to contribute to the development of balance problems in the early phase of MS. Therefore, the aim was to evaluate balance and gait performance in pwMS with the absence of clinical disability (AD) for comparison with pwMS with minimal disability (MD) and healthy controls (HC).

\section{Materials and Methods}

\section{Subjects}

Participants in the study were 35 pwMS undergoing routine control to outpatient MS Clinic of Dokuz Eylul University Hospital, and 39 healthy individuals attending or training at Dokuz Eylul University Health Campus. All of the patients were relapsing-remitting MS (RRMS). Demographic data (sex, age, education, marital status, MS diagnosis year, and MS type) were recorded. The same neurologist examined the MS subjects for the suitability and calculated the Expanded Disability Status scale (EDSS). During the posturographic assessments [postural stability (PS), limits of stability (LOS), falling risks index (FRI)], a physiotherapist was present to prevent fall risk. All subjects wore suitable clothes and shoes.

Inclusion criteria for patients had MS diagnosis according to the McDonald criteria (7), no problems with balance, EDSS score $\leq 3.0$, nearly full visual capability, and willingness to participate in the study. Exclusion criteria were having a neurologic disease other than MS, a relapse in the last month, walking disturbance with clinical evidence, depression, previous foot, knee or hip surgery and orthopedic disorders such as arthritis, back pain that limit the ability to walk and balance, and visual impairment. PwMS were divided into two groups clinically based on EDSS. The first group (EDSS $\leq 1.5$ ) included 19 pwMS with the AD, and the second MS group (EDSS 2.0-3.0) comprised 16 pwMS with minimal disability.

The Non-invasive Research Ethics Board of Dokuz Eylul University (decision number: 2016/18-20) approved the study and all subjects gave written informed consent.

\section{Balance and Gait Assessment}

The balance and fall risk was assessed through tests using the Biodex Stability System (Biodex Inc., Shirley, New York). Biodex stability system consists of a balance platform connected with computer software, which was used for evaluating the PS, the anteroposterior (AP) stability, the mediolateral (ML) stability, LOS and the FRI. Participants first performed PS tests. They were requested to stand upright and maintain stability for 20 seconds, using a screen, which shows the center of gravity as a black point. Then LOS (forward, backward, left, right) tests and fall risk tests were performed, respectively. Subjects were requested to use only their ankle joints and not the hip or knee joints to move different directions during LOS tests. In the fall risk test, the aim was to maintain PS as much as possible on a moving platform. Each test was performed three times. Postural stability, stability limits, and fall risk scores were assessed in both the patients and healthy subjects.

The Brief-BESTest is a clinical balance measurement method (8), which consists of six sub-scores between $0-3$ points. Zero points indicate seriously affected balance, and 3 points, no balance problems.

The Activities-Specific Balance Confidence (ABC) scale was performed to assess self-confidence during the activities of daily living. This scale consists of 16 questions on the individual's confidence in their ability to maintain balance in different situations (9).

Gait speed was evaluated using the timed 25-foot walk test (T25FW). In the T25FW evaluating the lower extremity function, the individual was asked to walk 25 feet as quickly and safely as possible. T25FW is the best-defined method for measuring gait disturbance in pwMS (10). The test was conducted with both patients with MS and healthy subjects.

The 12-Item MS walking scale (MSWS-12) was used to evaluate walking ability. This scale assesses walking limitations over two weeks in pwMS. Higher scores indicate a more significant effect on walking ability (11). MSWS-12 was applied only to patients. This scale detects the complicated impact of MS on walking (12).

\section{Statistical Analysis}

Sample size was calculated using the G*Power software (version 3.1.9.4, Düsseldorf University, Germany). The effect size of difference in the T25FW was reported as 1.04 between 
people with MS with mild and moderate disability levels (13). For power $=0.95$, alpha error value $=0.05$ and effect size $=1.04$, the sample size was calculated as 16 for each group. The data were analyzed using the SPSS Statistics for Windows (version 17.0; SPSS Inc., Chicago, USA). The normality of the distribution of data was checked using the Kolmogorov-Smirnov test and histograms. In cases where the data were normally distributed, the groups were compared using the independent groups t-test. The Mann-Whitney U test was performed when normal distribution was not achieved. Bonferroni correction was performed because of the three groups. The relationship between the variables was investigated using pearson's correlation coefficient when there was normal distribution, and Spearman's correlation coefficient otherwise. The statistical significance level was set at $\mathrm{p}<0.05$.

\section{Results}

The PwMS-AD group comprised four males and 15 females with a mean $32.3 \pm 7.35$ (range, 23 to 51 ) years. The pwMS-MD group was constituted by four males and 12 females, with a mean age of 38.1 (range, 18-53) years. The HC group comprised of 9 males and 30 females, with a mean age of 34.1 years (range, 22-61). There were no statistically significant differences in descriptive statistics between the groups in terms of age, height or body weight. Frequency and percentage distribution according to sex, educational status, and working status revealed that the groups were not significantly different. The characteristics of the groups are presented in Table 1.

\section{Balance and Gait Parameters}

Based on the Mann-Whitney U tests, significant differences were found between pwMS-AD and HC in all domains of LOS scores [overall $(p<0.001)$, forward $(p<0.001)$, left $(p=0.021)$, and right $(\mathrm{p}<0.001)]$ with an exception of the difference in LOS backward score $(\mathrm{p}=0.135)$. There was also a significant difference in PS ML ( $\mathrm{p}=0.036)$, FRI $(\mathrm{p}=0.042)$, Brief-BESTest $(\mathrm{p}<0.001)$

\begin{tabular}{|llll|}
\hline Table 1. Characteristics of the groups & & \\
Variables & $\begin{array}{l}\text { pwMS-AD } \\
(\mathbf{n}=19)\end{array}$ & $\begin{array}{l}\text { pwMS-MD } \\
(\mathbf{n}=16)\end{array}$ & $\begin{array}{l}\text { Controls } \\
(\mathbf{n}=39)\end{array}$ \\
Sex (female/male), $\mathrm{n}$ & $15 / 4$ & $12 / 4$ & $30 / 9$ \\
Age (years) & $32.3(7.3)$ & $38.1(12.0)$ & $34.1(10.4)$ \\
Height (m) & $1.66(0.11)$ & $1.64(0.07)$ & $1.65(0.09)$ \\
Weight (kg) & $63(11)$ & $69(12)$ & $67(16)$ \\
Education, $\mathrm{n}$ & & & \\
Primary school & 1 & 2 & 3 \\
High school & 2 & 4 & 6 \\
University & 16 & 10 & 30 \\
Employment Status, $\mathrm{n}$ & & & 31 \\
Employed & 15 & 7 & 2 \\
Unemployed & 3 & 5 & 3 \\
Retired & 1 & 2 & 3 \\
Student & 0 & 2 & \\
PwMS: Persons with multiple sclerosis, AD: Absence of clinical disability, MD: \\
Minimal disability
\end{tabular}

and T25FW scores ( $\mathrm{p}=0.006)$, but no significant difference in the $\mathrm{ABC}$ scale score $(\mathrm{p}=0.543)$ between pwMS-AD and HC (Table 2$)$. According to the scores of T25FW ( $<<0.001), A B C(p<0.001)$ and Brief-BESTest $(p<0.001)$, significant differences were observed between the pwMS-MD and HC groups (Table 3). In addition, significant differences were found between pwMS-AD and pwMSMD in terms of PS scores [overall $(p=0.012)$, AP $(p=0.003), M L$ $(\mathrm{p}=0.036)$ ], Brief-BESTest $(\mathrm{p}=0.042), \mathrm{T} 25 \mathrm{FW}(\mathrm{p}=0.030)$, and

\begin{tabular}{|c|c|c|c|}
\hline Variables & $\begin{array}{l}\text { pwMS-AD } \\
(n=19)\end{array}$ & $\begin{array}{l}\text { Control } \\
(n=39)\end{array}$ & $\mathrm{p}$ \\
\hline $\mathrm{T} 25 \mathrm{FW}$ & $4.4(4,5)$ & $3.9(3.7,4.5)$ & $0.006^{*}$ \\
\hline ABC scale & $91(69,98)$ & $97(86,98)$ & 0.543 \\
\hline Brief-BESTest & $15(14,16)$ & $18(18,18)$ & $<0.001^{*}$ \\
\hline PS Overall & $0.3(0.3,0.4)$ & $0.3(0.2,0.3)$ & 0.072 \\
\hline PS AP & $0.2(0.2,0.3)$ & $0.2(0.2,0.3)$ & $>0.999$ \\
\hline PS ML & $0.2(0.1,0.2)$ & $0.1(0.1,0.1)$ & $0.036^{*}$ \\
\hline LOS Overall & $32(22,41)$ & $50(45,59)$ & $<0.001^{*}$ \\
\hline LOS Forward & $34(23,54)$ & $69(55,80)$ & $<0.001^{*}$ \\
\hline LOS Backward & $40(26,53)$ & $51(34,62)$ & 0.135 \\
\hline LOS Left & $46(33,67)$ & $65(55,74)$ & $0.021^{*}$ \\
\hline LOS Right & $39(34,54)$ & $62(52,71)$ & $<0.001$ \\
\hline FRI & $0.9(0.7,1.1)$ & $0.7(0.6,0.9)$ & $0.042^{*}$ \\
\hline \multicolumn{4}{|c|}{$\begin{array}{l}\text { "p }<0.05 \text {, data are expressed as median (interquartile range) } \\
\text { PwMS: Persons with multiple sclerosis, AD: Absence of clinical disability, } \\
\text { T25FW: Timed } 25 \text {-foot walk, ABC: Activities-specific Balance Confidence scale, } \\
\text { PS: Postural stability, AP: Anteroposterior, ML: Mediolateral, LOS: Limits of } \\
\text { stability, FRI: Fall risk index }\end{array}$} \\
\hline
\end{tabular}

Table 3. Balance and gait tests between pwMS-MD and controls

\begin{tabular}{|c|c|c|c|}
\hline Variables & $\begin{array}{l}\text { pwMS-MD } \\
(\mathrm{n}=16)\end{array}$ & $\begin{array}{l}\text { Control } \\
(n=39)\end{array}$ & $\mathrm{p}$ \\
\hline T25FW & $5.4(4.5,6.3)$ & $3.9(3.7,4.5)$ & $<0.001^{*}$ \\
\hline ABC scale & $68(36,90)$ & $97(86,98)$ & $<0.001 *$ \\
\hline Brief-BESTest & $11.5(11,15)$ & $18(18,18)$ & $<0.001^{*}$ \\
\hline PS Overall & $0.5(0.4,0.9)$ & $0.3(0.2,0.3)$ & $<0.001^{*}$ \\
\hline PS AP & $0.4(0.3,0.5)$ & $0.2(0.2,0.3)$ & $<0.001^{*}$ \\
\hline PS ML & $0.2(0.2,0.6)$ & $0.1(0.1,0.1)$ & $<0.001^{*}$ \\
\hline LOS Overall & $31(23,44.5)$ & $50(45,59)$ & $<0.001^{*}$ \\
\hline LOS Forward & $46.5(30,53)$ & $69(55,80)$ & $<0.001^{*}$ \\
\hline LOS Backward & $35.5(29.5,52)$ & $51(34,62)$ & 0.147 \\
\hline LOS Left & $44(30,53)$ & $65(55,74)$ & $<0.001^{*}$ \\
\hline LOS Right & $37.5(30,52)$ & $62(52,71)$ & $0.003^{*}$ \\
\hline FRI & $0.95(0.8,1.5)$ & $0.7(0.6,0.9)$ & $0.003^{*}$ \\
\hline \multicolumn{4}{|c|}{$\begin{array}{l}\text { "p } \mathrm{p}<0.05 \text {, data are expressed as median (interquartile range) } \\
\text { PwMS: Persons with multiple sclerosis, T25FW: Timed } 25 \text {-foot walk, ABC: } \\
\text { Activities-specific Balance Confidence scale, PS: Postural stability, AP: } \\
\text { Anteroposterior, ML: Mediolateral, LOS: Limits of stability, FRI: Fall risk index, } \\
\text { MD: Minimal disability }\end{array}$} \\
\hline
\end{tabular}


MSWS-12 ( $\mathrm{p}=0.009)$, but no significant difference was available between their LOS overall ( $p>0.999)$ and FR ( $\mathrm{p}=0.396)$, and ABC $(\mathrm{p}=0.129)$ scores (Table 4).

\section{Correlations Between the Performance-based and Clinical} or Self-reported Measures

Correlations between performance-based balance measures and clinical and self-assessment tools were investigated to understand whether these measurement methods were coherent with each other. All of the PS scores were significantly correlated with Brief-BESTest, ABC, and T25FW scores, but MSWS-12 was only correlated with the PS AP score $(\mathrm{p}<0.05)$. The results are shown in Table 5.

\begin{tabular}{|c|c|c|c|}
\hline Variables & $\begin{array}{l}\text { pwMS-AD } \\
(\mathrm{n}=19)\end{array}$ & $\begin{array}{l}\text { pwMS-MD } \\
(n=16)\end{array}$ & $\mathrm{p}$ \\
\hline T25FW & $4.4(4,5)$ & $5.4(4.5,6.3)$ & $0.030^{*}$ \\
\hline ABC scale & $91(69,98)$ & $68(36,90)$ & 0.129 \\
\hline Brief-BESTest & $15(14,16)$ & $11.5(11,15)$ & $0.042^{*}$ \\
\hline PS Overall & $0.3(0.3,0.4)$ & $0.5(0.4,0.9)$ & $0.012^{*}$ \\
\hline PS AP & $0.2(0.2,0.3)$ & $0.4(0.3,0.5)$ & $0.003^{*}$ \\
\hline PS ML & $0.2(0.1,0.2)$ & $0.2(0.2,0.6)$ & $0.036^{*}$ \\
\hline LOS Overall & $32(22,41)$ & $31(23,44.5)$ & $>0.999$ \\
\hline LOS Forward & $34(23,54)$ & $46.5(30,53)$ & $>0.999$ \\
\hline LOS Backward & $40(26,53)$ & $35.5(29.5,52)$ & $>0.999$ \\
\hline LOS Left & $46(33,67)$ & $44(30,53)$ & $>0.999$ \\
\hline LOS Right & $39(34,54)$ & $37.5(30,52)$ & $>0.999$ \\
\hline FRI & $0.9(0.7,1.1)$ & $0.95(0.8,1.5)$ & 0.396 \\
\hline MSWS-12 & $13(12,18)$ & $22.5(14,38)$ & $0.009^{*}$ \\
\hline \multicolumn{4}{|c|}{$\begin{array}{l}\text { "p }<0.05 \text {, data are expressed as median (interquartile range) } \\
\text { PwMS: Persons with multiple sclerosis, AD: Absence of clinical disability, } \\
\text { T25FW: Timed } 25-\text { foot walk, ABC: Activities-specific Balance Confidence scale, } \\
\text { PS: Postural stability, AP: Anteroposterior, ML: Mediolateral, LOS: Limits of } \\
\text { stability, FRI: Fall risk index, MSWS-12: 12-item multiple sclerosis walking scale, } \\
\text { MD: Minimal disability }\end{array}$} \\
\hline
\end{tabular}

\section{Discussion}

This study suggests that the pwMS-AD group had impaired balance and gait performance compared with $\mathrm{HC}$; however, subjective confidence in balance was not significantly different from HC. Although ML PS and stability limits (except backward LOS) were affected before disability occurred in pwMS, with the accuracy of minimal disability, AP PS and subjective confidence in balance became significantly different compared with the HC. It is, therefore, possible to conclude that ML PS and forward LOS might be affected earlier than AP PS and backward LOS in pwMS.

The causes of balance impairment in MS are not clearly known. To understand better how MS influences balance mechanisms, a more precise measurement of balance disturbances is needed (14). Many clinical scales and self-assessment methods have been used to evaluate balance deficits in pwMS (15). However, in this study, the Biodex Balance System was used as an objective method. Two additional tests were used: Brief-BESTest, which is a clinical scale, and the $\mathrm{ABC}$ scale, which is a self-assessment method of balance confidence. Brief-BESTest evaluates static and dynamic balance capabilities in pwMS. It is a sensitive method for determining changes following balance training and a more comprehensive clinical method than EDSS and T25FW for assessing balance disorders (16). However, it is still unclear as to whether BriefBESTest alone without an objective assessment tool is sufficient to distinguish between HC and patients in the early stages of MS. Also, in previous studies on minimally disabled pwMS, BriefBESTest was considered less sensitive than the instrumented sway measurements, but it had stronger associations with selfassessment measures than T25FW and EDSS (13). In our study, there was a significant and negative correlation between the Brief-BESTest total score and PS (overall, AP, ML) scores, but no significant correlation with LOS and FRI scores. According to the results, the Brief-BESTest is compatible with an objective assessment of postural stability, but it may not be sensitive enough to evaluate the LOS and fall risk for people in the early stage of MS.

The ABC scale, which enables self-assessment measurements, was included in this study to determine whether the subjective symptoms of balance and gait disturbances in the early stages of MS were consistent with objective measurements. Previous studies support that a wide variety of instrumental measurement

Table 5. Correlations between objective and clinical scales

$\begin{array}{lllll}\text { Variables } & \text { Brief-BESTest } & \text { ABC } & \text { T25FW } & \text { MSWS-12 } \\ \text { PS Overall } & -0.541^{*} & -0.480^{*} & 0.398^{*} & 0.311^{*} \\ \text { PS AP } & -0.575^{*} & -0.517^{*} & 0.412^{*} & 0.407^{*} \\ \text { PS ML } & -0.502^{*} & -0.429^{*} & 0.479^{*} & 0.317^{*} \\ \text { LOS Overall } & 0.289 & 0.156 & -0.197 & 0.271 \\ \text { LOS Forward } & 0.261 & 0.243 & -0.106 & 0.172 \\ \text { LOS Backward } & 0.267 & 0.144 & -0.245 & 0.215 \\ \text { LOS Left } & 0.258 & 0.136 & -0.125 & 0.120 \\ \text { LOS Right } & 0.225 & 0.147 & -0.148 & 0.002 \\ \text { FRI } & -0.316 & -0.109 & 0.215 & 0.129 \\ \text { "p<0.05 } & & & \\ \text { PwMS: Persons with multiple sclerosis, T25FW: Timed 25-foot walk, ABC: Activities-specific Balance Confidence scale, PS: Postural stability, AP: Anteroposterior, ML: } \\ \text { Mediolateral, LOS: Limits of stability, FRI: Fall risk index, MSWS-12: 12-item multiple sclerosis walking scale }\end{array}$


methods are compatible with the self-assessment measures used to determine impairment in individuals with MS $(17,18)$. According to our results, a significant and negative correlation was found between ABC scores and PS (overall, ML, AP) scores, showing compatibility between subjectively perceived balance and the objective PS data. Similarly, T25FW score significantly correlated with all of the PS scores, but not with other objective balance measures. Furthermore, the MSWS-12 score was only associated with the anterior PS score. This situation indicates that clinical and subject-reported measurements are more sensitive for evaluating static balance than dynamic balance and fall risk in the early stages of MS. Solomon et al. (14) also suggested that ABC and MSWS-12 were not sufficient to determine early postural abnormalities in minimally disabled pwMS.

Various studies have shown that walking and balance deficits are present even in subjects with RRMS with no or weak balance disorder, early in the disease $(19,20,21)$. In our study of subclinical dysfunction in the early stages of patients with RRMS, postural control deficits and increased fall risk were found in the pwMSMD group and the pwMS-AD group compared with healthy subjects.

Studies have shown that pwMS experience more variability in walking and take shorter and slower steps than controls. They also spend more time in the double support period of the walking cycle, which may affect walking quality and stability (22). Martin et al. (1) demonstrated that walking and balance disorders were present in individuals with MS without disability. They also reported that individuals with MS with a newly diagnosed, mild neurological disorder walked more slowly than HC, had shorter ankle joint motion with shorter step length, and had a change in ankle muscle activities. Reduced gait speed may, therefore, indicate compromised gait stability in pwMS (1).

According to the results of our study, despite the absence of disability, pwMS had ML postural instability, decreased limits of stability, and increased fall risk compared with $\mathrm{HC}$, and significantly slower walking speed. Thus, ML stability is affected in subjects with MS at earlier stages of the disease, and AP stability does not begin to deteriorate significantly until disability occurs. Similarly, in a previous study with minimally disabled subjects with MS, ML sway parameters were determinative between healthy and MS subjects (14). ML PS may therefore also be a responsive indicator of impaired balance performance, even in patients with MS without a disability.

When we examined the LOS tests, pwMS-AD had significant decreases in left, right, and forward stability limits, but not in the backward limit of stability. However, pwMS-MD demonstrated worse LOS in all directions, included backward stability limit, compared with HC. This situation suggests that the backward limit of stability may start to differentiate $\mathrm{HC}$ from pwMS with minimal disability. There is a decrease in the posterior center of pressure (COP) in pwMS because of the affected anticipatory mechanism. This difference in posterior displacement of COP is a compensatory strategy to reduce anterior push of the body center of mass, which allows safe walking and protects posterior stability limits (23). Due to this reduction in stability limits, there is a decrease in areas where pwMS can move comfortably and the effectiveness of anti-fall mechanisms can be restricted (24).

\section{Study Limitations}

Our study has some limitations. First, although posturography was used for objective balance evaluation, gait was evaluated with clinical scales only. Second, we had a small sample size. Third, the distributions of lesions in magnetic resonance imaging, which may have an impact on balance tests, were not taken into consideration. Further studies with a larger sample size are needed to investigate balance and gait impairment in persons with minimally disabled MS.

\section{Conclusion}

The results showed that the pwMS-AD have impaired balance and gait performance compared with $\mathrm{HC}$; however, subjective confidence in balance is not significantly different from HC. Although pwMS-AD have no awareness of their balance and gait impairment, they should be assessed regularly regarding balance with clinical and laboratory-based analysis tools. This can lead to the early detection of impaired balance and fall risk.

\section{Ethics}

Ethics Committee Approval: The Non-invasive Research Ethics Board of Dokuz Eylul University (decision number: 2016/18-20).

Informed Consent: The study and all subjects gave written informed consent.

Peer-review: Externally peer-reviewed.

\section{Authorship Contributions}

Concept: H.A., Ö.E., S.Ö., Design: H.A., Ö.E., S.Ö., Data Collection or Processing: H.A., Ö.E., T.K., S.Ö., Analysis or Interpretation: H.A., Ö.E., T.K., Literature Search: H.A., Ö.E., Writing: H.A., Ö.E.

Conflict of Interest: No conflict of interest was declared by the authors.

Financial Disclosure: The authors declared that this study received no financial support.

\section{References}

1. Martin CL, Phillips BA, Kilpatrick TJ, et al. Gait and balance impairment in early multiple sclerosis in the absence of clinical disability. Mult Scler 2006;12:620-628.

2. Koch-Henriksen N, Sørensen PS. The changing demographic pattern of multiple sclerosis epidemiology. The Lancet Neurology 2010;9:520-532.

3. Cattaneo D, Jonsdottir J. Sensory impairments in quiet standing in subjects with multiple sclerosis. Mult Scler 2009;15:59-67.

4. Kim HS, Yun DH, Yoo SD, et al. Balance control and knee osteoarthritis severity. Ann Rehabil Med 2011;35:701-709.

5. Fjeldstad C, Pardo G, Bemben D, Bemben M. Decreased postural balance in multiple sclerosis patients with low disability. Int J Rehabil Res 2011;34:5358.

6. Corradini ML, Fioretti S, Leo T, Piperno R. Early recognition of postural disorders in multiple sclerosis through movement analysis: A modeling study. IEEE Trans Biomed Eng 1997;44:1029-1038.

7. Polman $\mathrm{CH}$, Reingold SC, Banwell B, et al. Diagnostic criteria for multiple sclerosis: 2010 Revisions to the McDonald criteria. Ann Neurol 2011;69:292-302.

8. Franchignoni F, Giordano A. On "Is the BESTest at its best?..." Padgett PK, Jacobs JV, Kasser SL. Phys Ther. 2012;92:1197-1207. Physical Therapy 2012;92:1236-1237.

9. Powell LE, Myers AM. The Activities-specific Balance Confidence (ABC) Scale. The journals of gerontology Series A. J Gerontol A Biol Sci Med Sci 1995;50A:M28-M34 
10. Kieseier BC, Pozzilli C. Assessing walking disability in multiple sclerosis Mult Scler 2012;18:914-924.

11. Hobart JC, Riazi A, Lamping DL, Fitzpatrick R, Thompson AJ. Measuring the impact of MS on walking ability: the 12-Item MS Walking Scale (MSWS-12). Neurology 2003;60:31-36.

12. Motl RW, Snook EM. Confirmation and extension of the validity of the multiple sclerosis walking scale-12 (MSWS-12). J Neurol Sci 2008;268:6973.

13. Motl RW, Cohen JA, Benedict R, et al. Validity of the timed 25-foot walk as an ambulatory performance outcome measure for multiple sclerosis. Mult Scler 2017;23:704-710.

14. Solomon AJ, Jacobs JV, Lomond KV, Henry S. Detection of postural sway abnormalities by wireless inertial sensors in minimally disabled patients with multiple sclerosis: a case-control study. J Neuroeng Rehabil 2015;12:19.

15. Balcer LJ. Nanos symposium on optic neuritis and multiple sclerosis clinical outcome measures for research in Mult Scler 2001;21:296-301.

16. Jacobs JV, Kasser SL. Balance impairment in people with multiple sclerosis: Preliminary evidence for the balance evaluation systems test. Gait Posture 2012;36:414-418.

17. Corporaal SHA, Gensicke H, Kuhle J, et al. Balance control in multiple sclerosis: Correlations of trunk sway during stance and gait tests with disease severity. Gait Posture 2013;37:55-60.
18. Kanekar N, Aruin AS. The role of clinical and instrumented outcome measures in balance control of individuals with multiple sclerosis. Mult Scler Int 2013;2013:190162.

19. Soyuer F, Mirza M, Erkorkmaz U. Balance performance in three forms of multiple sclerosis. Neurol Research 2006;28:555-562.

20. Benedetti MG, Piperno R, Simoncini L, et al. Gait abnormalities in minimally impaired multiple sclerosis patients. Mult Scler 1999;5:363368.

21. Karst GM, Venema DM, Roehrs TG, Tyler AE. Center of pressure measures during standing tasks in minimally impaired persons with multiple sclerosis. J Neurol Phys Ther 2005;29:170-180.

22. Socie MJ, Sosnoff JJ. Gait variability and multiple sclerosis. Mult Scler Int 2013;2013:1-7.

23. Galli M, Coghe G, Sanna P, et al. Relationship between gait initiation and disability in individuals affected by multiple sclerosis. Mult Scler Relat Disord 2015;4:594-597.

24. Denommé LT, Mandalfino P, Cinelli ME. Understanding balance differences in individuals with multiple sclerosis with mild disability: an investigation of differences in sensory feedback on postural control during a Romberg task. Exp Brain Res 2014;232:1833-1842. 